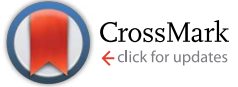

Cite this: RSC Adv., 2017, 7, 1206

Received 12th October 2016

Accepted 1st December 2016

DOI: 10.1039/c6ra25149h

www.rsc.org/advances

\title{
Enhancement of photocurrent in an ultra-thin perovskite solar cell by Ag nanoparticles deposited at low temperature $\uparrow$
}

\author{
Yang Liu, ${ }^{\star a b}$ Felix Lang, ${ }^{a}$ Thomas Dittrich, ${ }^{a}$ Alexander Steigert, ${ }^{a}$ \\ Christian-Herbert Fischer, ${ }^{b}$ Tristan Köhler, ${ }^{a}$ Paul Plate, ${ }^{a}$ Jörg Rappich, ${ }^{a}$ \\ Martha Ch. Lux-Steiner ${ }^{a}$ and Martina Schmid ${ }^{\star a c}$
}

\begin{abstract}
Ultra-thin perovskite absorber layers have attracted increasing interest since they are suitable for application in semi-transparent perovskite and tandem solar cells. In this study, size and density controlled plasmonic silver nanoparticles are successfully incorporated into ultra-thin perovskite solar cells through a low temperature spray chemical vapor deposition method. Incorporation of Ag nanoparticles leads to a significant enhancement of $22.2 \%$ for the average short-circuit current density. This resulted in a relative improvement of $22.5 \%$ for the average power conversion efficiency. Characterization by surface photovoltage and photoluminescence provides evidence that the implemented silver nanoparticles can enhance the charge separation and the trapping of electrons into the $\mathrm{TiO}_{2}$ layer at the $\mathrm{CH}_{3} \mathrm{NH}_{3} \mathrm{Pbl}_{3} / \mathrm{TiO}_{2}$ interface. The application of these silver nanoparticles therefore has promise to enhance the ultra-thin perovskite solar cells.
\end{abstract}

\section{Introduction}

In recent years, the inorganic-organic hybrid perovskites have attracted extremely high attention. ${ }^{1}$ They have many advantages, e.g., they can be processed by very simple, low cost methods and in parallel they have excellent electrical and optical properties. $^{2}$ The perovskite solar cell (PSC) power conversion efficiency (PCE) has sharply improved from the $3.81 \%$ first reported in 2009 to $22.1 \%$ in $2016 . .^{3,4}$ Early-stage PSCs had a similar architecture as dye-sensitized solar cells, employing a mesoporous metal oxide (normally $\mathrm{TiO}_{2}$ ) layer for electron transfer. ${ }^{5,6}$ Later, Snaith et al. found electrons can be transported through the perovskite absorber layer. ${ }^{7}$ This opened the gate for developing the planar heterojunction PSCs which further expanded the scope of application of PSCs. ${ }^{8-10}$ Based on the development of planar heterojunction PSCs, ultra-thin perovskite absorber layers which are much thinner than the perovskite absorber layers in normal PSCs became widely used and find application in semitransparent PSCs and tandem solar cells. ${ }^{11-14}$ However, due to the decrease of the layer thickness,

${ }^{a}$ Helmholtz-Zentrum Berlin für Materialien und Energie GmbH, Hahn-Meitner-Platz 1, 14109 Berlin, Germany. E-mail: yang.liu@helmholtz-berlin.de; martina.schmid@ helmholtz-berlin.de

${ }^{b}$ Freie Universität Berlin, Institute of Chemistry and Biochemistry, Fabeckstr. 34-36, 14195 Berlin, Germany

'Freie Universität Berlin, Department of Physics, Arnimallee 14, 14195 Berlin, Germany

$\dagger$ Electronic supplementary information (ESI) available. See DOI: $10.1039 / \mathrm{c} 6 \mathrm{ra} 25149 \mathrm{~h}$ the ultra-thin perovskite solar cells (UTPSCs) cannot give PCEs comparable to the bulk PSCs., ${ }^{\mathbf{9}, 11}$

To improve the PCE of solar cells without increasing the thickness of the absorber layer, the implementation of plasmonic nanoparticles has proved beneficial. ${ }^{15,16}$ Plasmonic nanoparticles can increase the effective light absorption of the absorber layer through plasmonic effects. ${ }^{15-17}$ This has been confirmed by the application of plasmonic nanoparticles in different kinds of solar cells, for example, in silicon solar cell, ${ }^{\mathbf{8}}$ in organic solar cell ${ }^{19}$ or in ultra-thin chalcopyrite solar cell. ${ }^{20}$ Hence, it is a promising way to use the same method to improve the PCE of perovskite solar cells. Although very interesting work has been reported on plasmonic enhanced PSCs, most of the nanoparticles were pre-synthesized and then implemented into the PSCs. ${ }^{21-26}$ That can be a drawback for the application in large scale PSCs. Moreover, several groups used Au nanoparticles for the plasmonic enhancement, which can dramatically increase the cost. $^{24,26}$

In this work, a spray chemical vapor deposition method (spray-CVD) ${ }^{27,28}$ was used for one step implementation of size and density controlled silver nanoparticles (Ag NPs) into UTPSC. The spray-CVD used here can easily be applied on large scale and the temperature used is much lower than that of the similar method reported in other work. ${ }^{29-32}$ The thickness of the perovskite absorber layer used is around $140 \mathrm{~nm}$, which is much thinner than the normal thickness ( $\sim 300 \mathrm{~nm}$ or even thicker). By implementation of Ag NPs, a significant enhancement of the short-circuit current density $\left(J_{\mathrm{sc}}\right)$ by $22.2 \%$ was obtained for the averaged performance of the solar cells, leading to a relative 
improvement of efficiency by $22.5 \%$. As confirmed by surface photovoltage (SPV) and photoluminescence (PL) study, the implemented Ag NPs can enhance charge separation and electron transfer to $\mathrm{TiO}_{2}$ layer, hence increase the photocurrent.

\section{Experimental details}

\section{Materials}

Commercial fluorine-doped tin oxide (FTO) glasses $\left(\sim 8 \Omega \mathrm{sq}^{-1}\right)$ were received from Solaronix. Acetone, ethanol, titanium diisopropoxide bis(acetylacetonate) ( $\left.\mathrm{Ti}(\mathrm{acac})_{2} \mathrm{OiPr}_{2}\right)$, lead iodide $\left(\mathrm{PbI}_{2}\right), \gamma$-butyrolactone (GBL) and dimethyl sulfoxide (DMSO), toluene, 4-tert-butylpyridine ( $t \mathrm{BP})$, bis(trifluoromethane) sulfonimide lithium salt (LiTFSI), acetonitrile (ACN), chlorobenzene (CBZ) were purchased from Sigma-Aldrich. Trimethylphosphine (hexafluoroacetylacetonato) silver $\left(\mathrm{Ag}(\mathrm{hfacac}) \mathrm{PMe}_{3}\right)$ were purchased from Strem Chemicals Inc. Methylammonium iodide (MAI) was received from DyeSol. 2,2' ,7, $7^{\prime}$-Tetrakis $(N, N$-di4-methoxy-phenyl-amino)-9,9'-spirobifluorene (spiro-OMeTAD) was purchased from 1-Material Inc. The purity of gold (Au) used for electrodes was $99.999 \%$. All the chemicals were used as received.

\section{Silver nanoparticles deposition}

$\mathrm{Ag}$ NPs were deposited on clean FTO/glass substrates by spray chemical vapor deposition. The precursor solution was prepared by dissolving $\mathrm{Ag}$ (hfacac) $\left(\mathrm{PMe}_{3}\right)$ in ethanol with a concentration of $10 \mathrm{mM}$. The precursor solution was nebulized to form an aerosol which was carried by nitrogen gas to the FTO glass substrate. The nitrogen flow rate was controlled to be 1 liter per minute and the substrate temperature was set to $110{ }^{\circ} \mathrm{C}$ during the deposition process. The deposition time was adjusted to $0.5,1$ and $5 \mathrm{~min}$ in order to vary the size (diameter from SEM) of the Ag NPs. The FTO glass substrates without Ag NP deposition were used as control samples.

\section{Ultra-thin perovskite solar cell fabrication}

FTO glass substrates $(2.35 \mathrm{~cm} \times 2.35 \mathrm{~cm})$ were cleaned by sonication in de-ionized water, acetone and ethanol for $20 \mathrm{~min}$ in each solvent and blown dry with nitrogen afterwards. The substrates were further cleaned by an Ar plasma treatment for 5 min. The compact $\mathrm{TiO}_{2}$ layer was deposited onto the cleaned FTO glass substrates with or without Ag NPs by spray pyrolysis using titanium diisopropoxide bis(acetylacetonate) as precursor. The concentration of the precursor solution and the substrate temperature were $6.8 \mathrm{mM}$ and $460{ }^{\circ} \mathrm{C}$, respectively. After the deposition of the compact $\mathrm{TiO}_{2}$ layer, all samples were transferred into a glove box with a $\mathrm{H}_{2} \mathrm{O}$ and $\mathrm{O}_{2}$ level less than $0.1 \mathrm{ppm}$. A stoichiometric $\mathrm{CH}_{3} \mathrm{NH}_{3} \mathrm{PbI}_{3}$ precursor solution with a concentration of $0.8 \mathrm{M}$ was prepared by dissolving $\mathrm{PbI}_{2}$ and $\mathrm{MAI}$ in $1 \mathrm{~mL}$ mixed solvent from $0.7 \mathrm{~mL}$ GBL and $0.3 \mathrm{~mL}$ DMSO. The solution was then stirred at $60{ }^{\circ} \mathrm{C}$ for $12 \mathrm{~h}$. An $\sim 140 \mathrm{~nm}$ thick $\mathrm{CH}_{3} \mathrm{NH}_{3} \mathrm{PbI}_{3}$ layer was deposited by spin coating the $\mathrm{CH}_{3} \mathrm{NH}_{3} \mathrm{PbI}_{3}$ solution at $1000 \mathrm{rpm}$ for $10 \mathrm{~s}$ and $5000 \mathrm{rpm}$ for $20 \mathrm{~s}$. For each speed, there were $5 \mathrm{~s}$ for increasing from 0 or $1000 \mathrm{rpm}$ to the desired speed. At $35 \mathrm{~s}$ of the spin coating step, $150 \mu \mathrm{L}$ of toluene was dripped onto the samples. The obtained $\mathrm{CH}_{3} \mathrm{NH}_{3} \mathrm{PbI}_{3}$ layer was annealed on a hot plate at $100{ }^{\circ} \mathrm{C}$ for $10 \mathrm{~min}$. Details of the corresponding process can be found elsewhere. ${ }^{33}$ After the sample had cooled down to room temperature, a layer of spiro-OMeTAD was deposited onto the perovskite layer by spin coating at $2000 \mathrm{rpm}$ for $40 \mathrm{~s}$. The precursor solution of spiro-OMeTAD was prepared

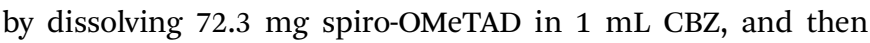
adding $17.5 \mu \mathrm{L} t \mathrm{BP}$ and $46.4 \mu \mathrm{L}$ LiTFSI solution $\left(170 \mathrm{mg} \mathrm{mL}^{-1}\right.$ in $\mathrm{ACN})$. Finally, gold back contacts with a thickness of $80 \mathrm{~nm}$ were deposited by thermal evaporation to finish the fabrication of the solar cells.

\section{Characterization}

The morphology of the Ag NPs and the thicknesses of each layer in the perovskite solar cell were studied by a scanning electron microscope (SEM, Gemini LEO1530 system) with an in-lens detector. The crystal structures of $\mathrm{Ag} \mathrm{NPs}$ and the $\mathrm{TiO}_{2}$ layer were studied by X-ray diffraction (XRD) with a Bruker D8 X-ray diffractometer operated in the gracing incidence mode with irradiation by a $\mathrm{Cu} \mathrm{K} \alpha$ source. Transmission and reflection spectra were measured using a Lambda 950 spectrophotometer with an integrating sphere. Absorption spectra were obtained by subtracting transmission and reflection from 100\%. The surface of the samples before deposition of the perovskite layer was measured by X-ray photoelectron spectroscopy (XPS). Mg $\mathrm{K} \alpha(1253.6 \mathrm{eV})$ radiation from a SPECS XR 50 X-ray gun served as excitation source. The emitted photoelectrons were detected by a CLAM 4 electron spectrometer from Thermo VG Scientific. Charge separation and transport length $(L)$ of photo-generated charge carriers were studied by SPV measurements. ${ }^{34-37}$ In the measurement of $L$, the SPV signal is kept constant whereas the light intensity is plotted depending on the absorption length (Goodman plot). The intersection point of the corresponding linear fit gives the negative value of $L .^{36,37}$ PL was measured using lasers of two wavelengths, $362 \mathrm{~nm}$ and $504 \mathrm{~nm}$. For both SPV and PL measurements, the light incident through the glass side. The samples didn't have a spiro-OMeTAD layer and Au back contact, instead a PMMA layer was deposited on top of the perovskite layer for the samples used in SPV measurements. ${ }^{34}$ Current-voltage $(J-V)$ curves of perovskite solar cells were measured using a "Steuernagel Lichttechnik" sun simulator, imitating an AM 1.5G spectra. The effective area of the solar cell was defined as $0.16 \mathrm{~cm}^{2}$ by the Au electrode. All $J-V$ curves were measured in both forward (from negative to positive) and reverse direction. The delay time and acquisition time were set as $40 \mathrm{~ms}$ and $20 \mathrm{~ms}$, respectively, leading to a scan speed of $0.167 \mathrm{~V} \mathrm{~s}^{-1}$. External quantum efficiency (EQE) spectra were measured by a specially designed EQE system in the wavelength range of $300-850 \mathrm{~nm}$.

\section{Results and discussion}

\section{Performance and architecture of ultra-thin perovskite solar cells with and without Ag NPs}

Fig. 1a shows the cross sectional SEM image of UTPSC without integration of $\mathrm{Ag}$ nanoparticles. A dense $\sim 35 \mathrm{~nm}$ thin $\mathrm{TiO}_{2}$ layer 

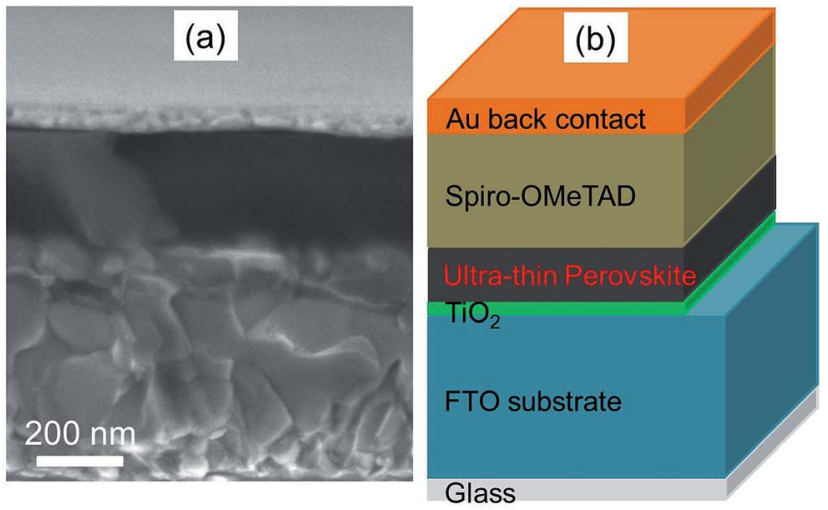

Fig. 1 (a) Cross sectional SEM image of ultra-thin perovskite solar cell. (b) Schematic device structure of ultra-thin perovskite solar cell.

was first deposited on top of the FTO/glass substrate by spray pyrolysis, and then a continuous and uniform ultra-thin $\mathrm{CH}_{3}-$ $\mathrm{NH}_{3} \mathrm{PbI}_{3}$ perovskite layer $(\sim 140 \mathrm{~nm})$ was deposited. Afterwards a hole conducting spiro-OMeTAD layer was spin coated on top, an $\mathrm{Au}$ back contact layer was evaporated last to finish the fabrication of the perovskite solar cell. Fig. 1b illustrates the schematic structure of the UTPSC. It has to be mentioned that the efficiency limit of the UTPSCs with $140 \mathrm{~nm}$ thick perovskite layer is approximately $24 \%$ which is lower than that of $31 \%$ for standard PSCs. ${ }^{38}$ To the best of the authors' knowledge, reported efficiencies of the UTPSCs with around $140 \mathrm{~nm}$ thick perovskite layer are lower than $15 \%{ }^{11-13,39}$

By $J-V$ measurements, the effect of Ag NPs on the performance of UTPSCs was investigated. Fig. 2a shows the schematic structure of UTPSC with integration of Ag NPs at the $\mathrm{TiO}_{2} / \mathrm{FTO}$ interface. In all the figures, a schematic structure of the samples used for each measurement is shown to facilitate understanding. Fig. $2 \mathrm{~b}$ presents $J-V$ curves of the best UTPSCs with and without $\mathrm{Ag}$ NPs selected from more than 20 devices. Diameters of Ag NPs varied from $11 \mathrm{~nm}$ to $16 \mathrm{~nm}$. In the content afterwards, the UTPSC without Ag NPs is named as control sample while the UTPSCs with $11 \mathrm{~nm}$ and $16 \mathrm{~nm}$ Ag NPs are named as $11 \mathrm{~nm} \mathrm{Ag} \mathrm{NP} \mathrm{sample} \mathrm{and} 16 \mathrm{~nm} \mathrm{Ag} \mathrm{NP} \mathrm{sample,}$ respectively. The control sample exhibited $1.02 \mathrm{~V}$ open circuit voltage $\left(V_{\mathrm{oc}}\right), J_{\mathrm{sc}}=14.07 \mathrm{~mA} \mathrm{~cm}{ }^{-2}$, and Fill Factor $(\mathrm{FF})=0.58$, leading to a PCE of $8.28 \%$. With implementation of different sizes of Ag NPs, $V_{\text {oc }}$ of the UTPSCs decreases from $1.02 \mathrm{~V}$ to $0.99 \mathrm{~V}$ (both $11 \mathrm{~nm}$ and $16 \mathrm{~nm} \mathrm{Ag} \mathrm{NP} \mathrm{sample).} \mathrm{This} \mathrm{can} \mathrm{be} \mathrm{due} \mathrm{to}$ the Ag NPs acting as recombination center in the UTPSCs. ${ }^{26,34}$ However, $J_{\mathrm{sc}}$ of the UTPSCs first increases from $14.04 \mathrm{~mA} \mathrm{~cm}^{-2}$ of the control sample to $15.93 \mathrm{~mA} \mathrm{~cm}^{-2}$ of the $11 \mathrm{~nm} \mathrm{Ag} \mathrm{NP}$ sample ( $13.5 \%$ increase compared to the control sample), then increases less to $15.83 \mathrm{~mA} \mathrm{~cm}^{-2}$ for the $16 \mathrm{~nm} \mathrm{Ag} \mathrm{NP} \mathrm{sample}$ (12.7\% increase compared to control sample). FF of the $11 \mathrm{~nm}$ $\mathrm{Ag}$ NP sample is 0.58 which is the same as the control sample while for the $16 \mathrm{~nm} \mathrm{Ag} \mathrm{NP} \mathrm{sample} \mathrm{FF}$ is 0.54 which is a bit lower. The increase of $J_{\mathrm{sc}}$ leads to the increase of PCE from $8.28 \%$ for the control sample to $9.14 \%$ for the $11 \mathrm{~nm} \mathrm{Ag} \mathrm{NP} \mathrm{sample} \mathrm{and}$ $8.40 \%$ for the $16 \mathrm{~nm} \mathrm{Ag}$ NP sample. The relative increase of PCE by incorporating $11 \mathrm{~nm}$ and $16 \mathrm{~nm} \mathrm{Ag}$ NPs are $10.4 \%$ and $1.4 \%$, respectively. Due to the decrease of $V_{\mathrm{oc}}$, the increase of PCE is not as high as the one in $J_{\text {sc. }}$.

To ensure the reliability of the enhancement, more than 20 devices were prepared for each configuration in three batches. The average device performance parameters are presented in Fig. 2c. For the $11 \mathrm{~nm}$ Ag NP samples, an average $J_{\mathrm{sc}}$ of $13.19 \mathrm{~mA}$ $\mathrm{cm}^{-2}$ was achieved, which is $22.2 \%$ higher than the average $J_{\mathrm{sc}}$ of $10.79 \mathrm{~mA} \mathrm{~cm}^{-2}$ for the control samples. At the same time, the average $J_{\mathrm{sc}}$ is $12.21 \mathrm{~mA} \mathrm{~cm}^{-2}$ for the $16 \mathrm{~nm} \mathrm{Ag} \mathrm{NP} \mathrm{samples,} \mathrm{which}$ is $13.2 \%$ higher than that of the control samples. The average FF of $11 \mathrm{~nm} \mathrm{Ag}$ NP samples is 0.55 while that of $16 \mathrm{~nm} \mathrm{Ag} \mathrm{NP}$ samples is 0.54 , both of which are higher than 0.52 for the control samples. The increase of both $J_{\mathrm{sc}}$ and FF leads to the improvements of the average PCE from $5.78 \%$ for the control samples to $7.08 \%$ (22.5\% relative) for the $11 \mathrm{~nm} \mathrm{Ag} \mathrm{NP} \mathrm{samples} \mathrm{and} \mathrm{to} \mathrm{6.38 \%}$ (10.5\% relative) for the $16 \mathrm{~nm} \mathrm{Ag} \mathrm{NP} \mathrm{samples.} \mathrm{Therefore,} \mathrm{it's}$ confirmed that the incorporation of Ag NPs can improve the device performance of UTPSC by enhancing the photocurrent. It has to be pointed out that in each batch the enhancement of $J_{\mathrm{sc}}$ and PCE by incorporating Ag NPs has the same trend (shown in Fig. S1†). The consistency of the enhancement in different batches confirmed again the influence of Ag NPs on UTPSCs. However, it is also observed that $V_{\text {oc }}$ decreased clearly due to the integration of both $11 \mathrm{~nm}$ and $16 \mathrm{~nm} \mathrm{Ag} \mathrm{NPs,} \mathrm{which} \mathrm{lowers} \mathrm{the}$ increase of average PCE for both the $11 \mathrm{~nm}$ and $16 \mathrm{~nm} \mathrm{Ag}$ NPs samples. If the decrease of $V_{\mathrm{oc}}$ can be prevented, higher improvement of PCE can be expected.

Fig. 2 shows the reverse scan performances of the UTPSCs. Fig. $\mathrm{S} 2 \dagger$ presents the hysteresis performances of the best control, $11 \mathrm{~nm} \mathrm{Ag}$ NP and $16 \mathrm{~nm} \mathrm{Ag}$ NP samples. Fig. S3† shows the average forward scan performances of the same samples shown in Fig. 2c, the differences agreed well with the reverse scan behavior. In addition, Fig. S4 $\uparrow$ shows the $V_{\mathrm{oc}}$ and $J_{\mathrm{sc}}$ histogram of the control samples and of the $11 \mathrm{~nm} \mathrm{Ag} \mathrm{NP}$ samples. Gaussian fitting for these four histograms confirmed the increase of $J_{\mathrm{sc}}$ and decrease of $V_{\text {oc }}$ caused by the incorporation of $11 \mathrm{~nm} \mathrm{Ag}$ NPs in the UTPSCs.

To understand the mechanism of the photocurrent enhancement and decrease of $V_{\text {oc }}$ caused by the integration of Ag NPs, different kinds of characterization were carried out.

\section{Morphology, optical properties of Ag nanoparticles and stabilization by $\mathrm{TiO}_{2}$ layer}

SEM images of FTO substrates without and with different sizes of Ag NPs are presented in Fig. 3b-e. Fig. 3a shows the structure of Ag NPs on top of FTO coated glass substrate. Sizes of the Ag NPs are $11 \mathrm{~nm}$ (Fig. 3c), $16 \mathrm{~nm}$ (Fig. 3d) and $36 \mathrm{~nm}$ (Fig. 3e), and they were prepared by simple variation of the deposition time using low temperature $\left(110^{\circ} \mathrm{C}\right)$ spray CVD. It is observed that in all three cases the sizes of the Ag NPs varied little, which can be recognized as nearly mono-dispersed. It has to be pointed out that the temperature of $110^{\circ} \mathrm{C}$ used to deposit Ag NPs was much lower than the reported work using spray pyrolysis to form $\mathrm{Ag}$ NPs. ${ }^{29-32}$ This low temperature, size and density controlled Ag NPs deposition method has high potential for wide use in different applications. 
(a)

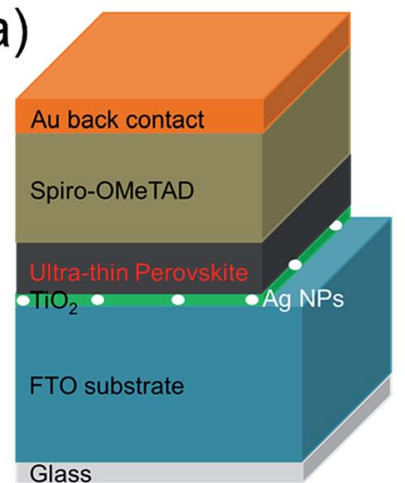

(b)

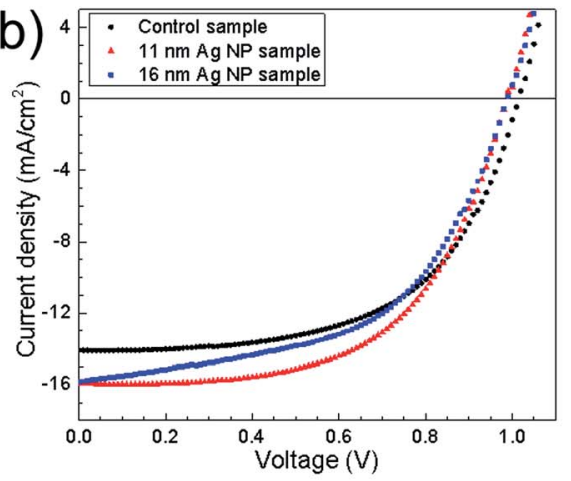

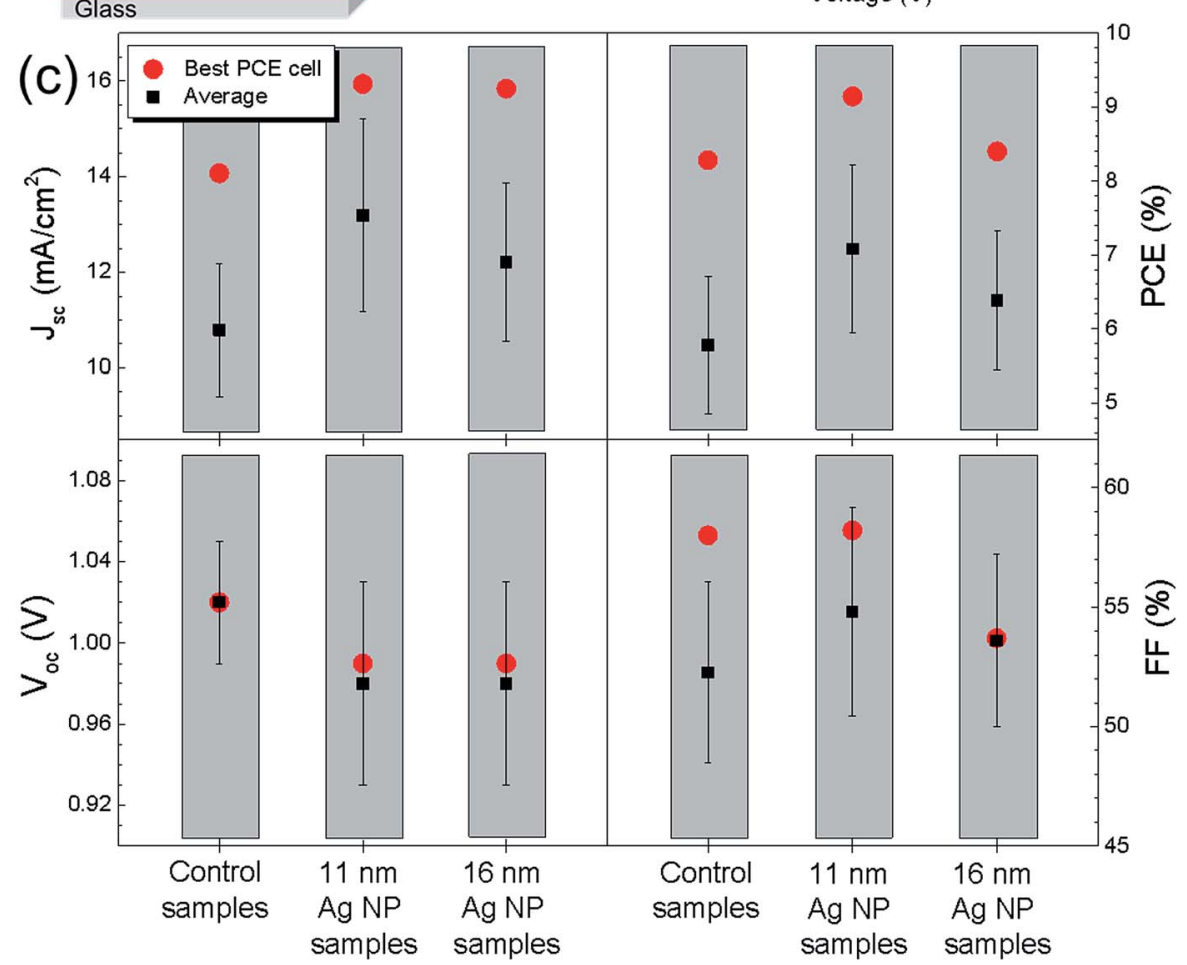

Fig. 2 (a) Schematic device structure of ultra-thin perovskite solar cell with incorporation of Ag nanoparticles at the $\mathrm{TiO}_{2} / \mathrm{FTO}$ interface. (b) $\mathrm{J}-\mathrm{V}$ curves of the best PCE ultra-thin perovskite solar cells without, with $11 \mathrm{~nm}$ and with $16 \mathrm{~nm} \mathrm{Ag} \mathrm{NPs} \mathrm{(i.e.} \mathrm{control} \mathrm{sample,} 11 \mathrm{~nm}$ Ag NP sample and 16 $\mathrm{nm}$ Ag NP sample). (c) Average device performances of control samples, $11 \mathrm{~nm}$ Ag NP samples and $16 \mathrm{~nm}$ Ag NP samples measured by reverse scan. For each condition, more than 20 devices were fabricated and measured.

Optical properties of Ag NPs deposited on FTO substrates were studied by UV-Vis measurements. Reflection and transmission of the three samples were recorded and the absorption of each sample was calculated (shown in Fig. 3f). Compared to the FTO/glass substrate, the absorption is clearly enhanced for the three Ag NP samples. The significant absorption enhancement from the $11 \mathrm{~nm} \mathrm{Ag} \mathrm{NP} \mathrm{sample} \mathrm{to} \mathrm{the} 36 \mathrm{~nm}$ Ag NP sample is due to the increase of both size and coverage. In all three cases with Ag NPs (11 nm, $16 \mathrm{~nm}$ and $36 \mathrm{~nm}$ ) an absorption peak around $430 \mathrm{~nm}$ is observed.

Fig. 4a presents the structure in which the Ag NPs on top of FTO coated glass substrate were covered by a $\mathrm{TiO}_{2}$ compact layer. Fig. 4b-e show the SEM images for the samples from Fig. 3b-e with covering of an additional $\mathrm{TiO}_{2}$ thin layer. For all the samples in Fig. $4 \mathrm{~b}-\mathrm{e}$, the thin $\mathrm{TiO}_{2}$ layers were very homogeneous and followed the structure of FTO surface. Almost no
Ag NPs can be observed from Fig. 4c-e, which means that all Ag NPs were covered by the $\mathrm{TiO}_{2}$ layer. In Fig. 4e, the distances between the Ag NPs nearly don't change compared to the same sample without $\mathrm{TiO}_{2}$ coating (Fig. 3e). This indicates that the Ag NPs on the surface of FTO were stabilized at their original positions by the $\mathrm{TiO}_{2}$ compact layer.

Absorption spectra of the samples in Fig. 4b-e are shown in Fig. S5 (ESI $\dagger$ ). Compared to the absorption spectra of the same samples before the deposition of $\mathrm{TiO}_{2}$ layers (shown in Fig. 3f) there are significant red shifts of the Ag NPs' resonance peaks. The red shifts of resonance peaks from around $430 \mathrm{~nm}$ to $540 \mathrm{~nm}$ can be attributed to the increase of refractive index of medium surrounding the $\mathrm{Ag}$ NPs which is caused by the deposition of $\mathrm{TiO}_{2}$ layer. As the $\mathrm{CH}_{3} \mathrm{NH}_{3} \mathrm{PbI}_{3}$ perovskite layer can convert light with wavelengths between $300 \mathrm{~nm}$ and $\sim 800 \mathrm{~nm}$ to electron-hole pairs, plasmonic effects of the Ag NPs 
(a)
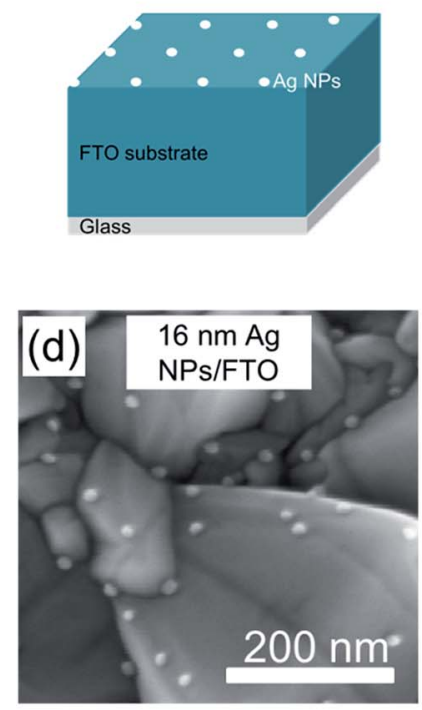
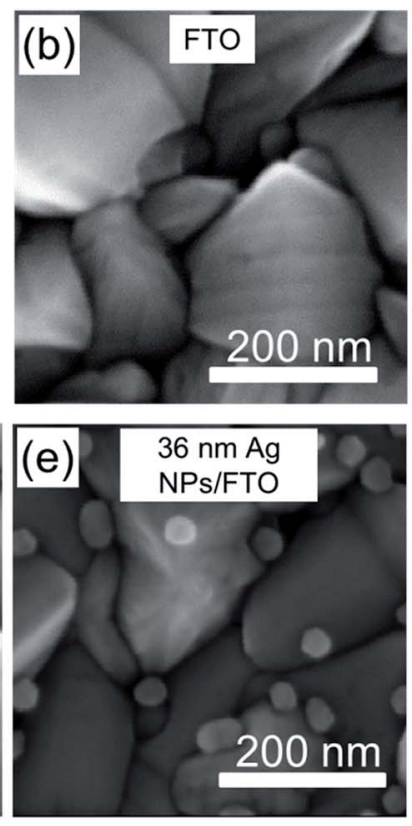
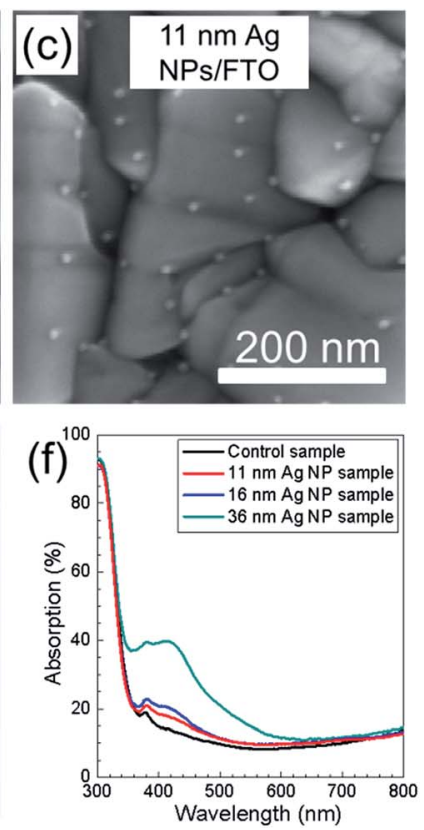

Fig. 3 (a) Schematic sample structure of Ag NPs on top of FTO coated glass substrate. (b-e) SEM images of FTO coated glass substrates without (b) and with $11 \mathrm{~nm}$ Ag NPs (c), $16 \mathrm{~nm}$ Ag NPs (d), $36 \mathrm{~nm}$ Ag NPs (e) on top. (f) UV-Vis absorption spectra of FTO coated glass substrate and with different sizes of Ag NPs on top.

with a resonance peak in that wavelength range could be exploited to enhance the performance of such perovskite solar cell.

A typical series of XPS spectra is shown in Fig. $4 \mathrm{f}$. The most interesting peak is the $\mathrm{Ag} 3 \mathrm{~d} \mathrm{5/2}$ core level with a binding energy of $368.3 \mathrm{eV}$ which is typically assigned to the pure $\mathrm{Ag}$ element.
For the samples shown in Fig. $4 \mathrm{~b}-\mathrm{e}$, as the $\mathrm{TiO}_{2}$ layers were very thin $(\sim 35 \mathrm{~nm})$, XPS measurements were taken to investigate whether the Ag NPs were fully covered by $\mathrm{TiO}_{2}$ layer. It is observed that there is no Ag signal detected on the control sample, but Ag signals are detected on the surface of $\mathrm{TiO}_{2}$ for all the samples with Ag NPs. With increase of particle size from
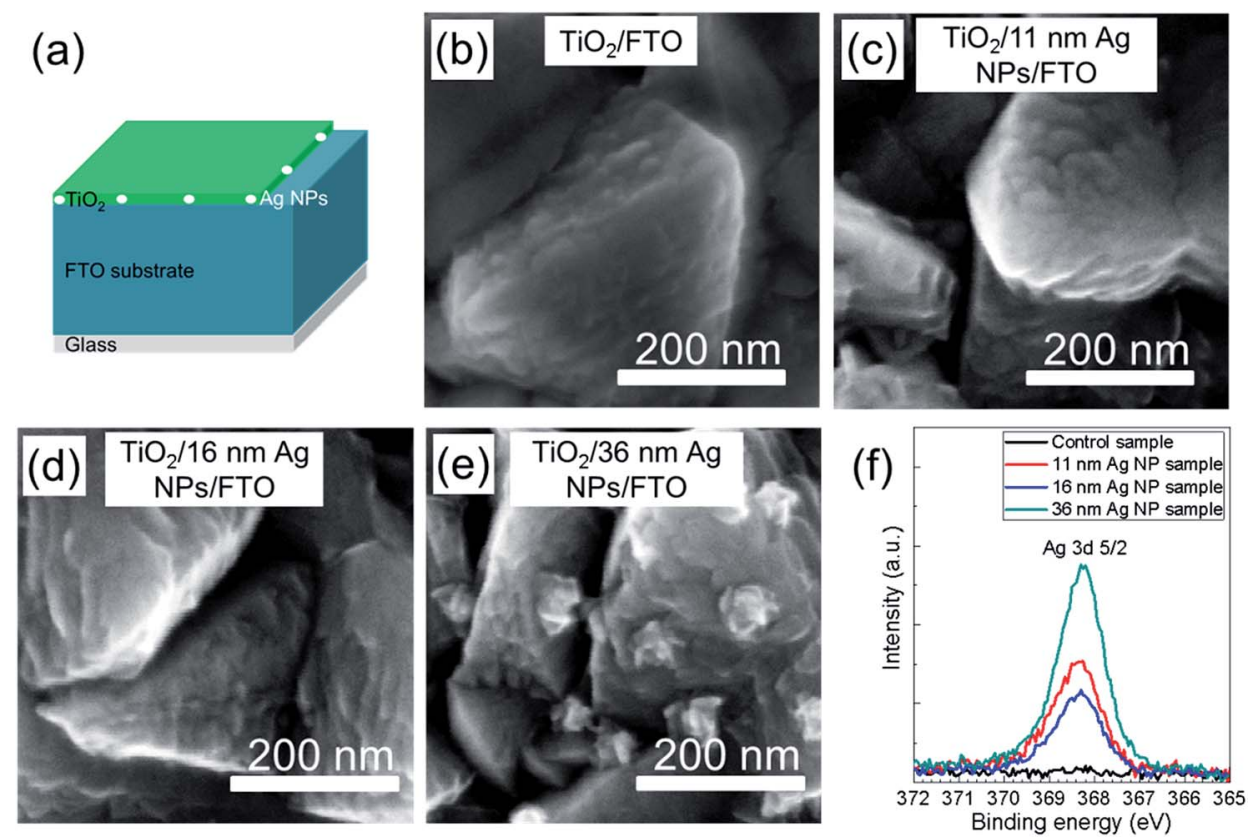

Fig. 4 (a) Schematic sample structure of $\mathrm{TiO}_{2} / \mathrm{Ag} \mathrm{NPs} / \mathrm{FTO} / g$ lass. (b-e) SEM images of $\mathrm{TiO}_{2}$ layer coated on $\mathrm{FTO}$ coated glass substrates without (b) and with $11 \mathrm{~nm} \mathrm{Ag} \mathrm{NPs} \mathrm{(c),} 16 \mathrm{~nm}$ Ag NPs (d), $36 \mathrm{~nm} \mathrm{Ag} \mathrm{NPs} \mathrm{(e)} \mathrm{on} \mathrm{top.} \mathrm{(f)} \mathrm{XPS} \mathrm{spectra} \mathrm{of} \mathrm{Ag} \mathrm{3d} \mathrm{5/2} \mathrm{core} \mathrm{level} \mathrm{measured} \mathrm{on} \mathrm{compact} \mathrm{TiO}{ }_{2}$ layers, which cover the bare FTO substrate (control sample) and FTO substrates with $11 \mathrm{~nm}$ Ag NPs, $16 \mathrm{~nm}$ Ag NPs and $36 \mathrm{~nm}$ Ag NPs, respectively. 
$11 \mathrm{~nm}$ to $36 \mathrm{~nm} \mathrm{Ag} \mathrm{NPs,} \mathrm{the} \mathrm{detected} \mathrm{Ag} \mathrm{signal} \mathrm{intensity}$ increases. Interestingly, the Ag signal intensity of the $16 \mathrm{~nm} \mathrm{Ag}$ NP sample is smaller than that of $11 \mathrm{~nm} \mathrm{Ag} \mathrm{NP} \mathrm{sample.}$ According to the XPS results, the Ag NPs are not fully covered by $\mathrm{TiO}_{2}$ or there is diffusion of $\mathrm{Ag}$ to the surface of $\mathrm{TiO}_{2}$. Both of the possibilities can cause the direct contact between perovskite layer and Ag NPs, leading to the formation of recombination centers at the interface between perovskite and $\mathrm{TiO}_{2}$ layer.

Although from Fig. 4c-e it looks like the shape of the Ag NPs doesn't change, it is hard to confirm from SEM images only whether the particles underneath $\mathrm{TiO}_{2}$ are still Ag NPs and whether there is significant $\mathrm{Ag}$ doped $\mathrm{TiO}_{2}$. To investigate this, XRD measurements were carried out. Fig. S6† gives XRD spectra for $\mathrm{Ag}$ NPs/glass, $\mathrm{TiO}_{2} /$ glass and $\mathrm{TiO}_{2}$ covered $\mathrm{Ag}$ NPs/glass. Characteristic peaks of Ag (JCPDS Files no.: 04-0783) and $\mathrm{TiO}_{2}$ (JCPDS Files no.: 21-1272) are marked in the figure. Only peaks of $\mathrm{Ag}$ are detected for the Ag NPs/glass sample and only peaks of $\mathrm{TiO}_{2}$ are observed for the $\mathrm{TiO}_{2} /$ glass sample. For the sample after deposition of the $\mathrm{TiO}_{2}$ layer onto the Ag NPs, peaks of both $\mathrm{Ag}$ and $\mathrm{TiO}_{2}$ are observed and all the peaks can be attributed to $\mathrm{Ag}$ and $\mathrm{TiO}_{2}$. Moreover, there is no shift of the $\mathrm{TiO}_{2}$ peaks observed after the deposition of $\mathrm{TiO}_{2}$ layer on top of Ag NPs which is different from the formation of $\mathrm{Ag}$ doped $\mathrm{TiO}_{2}$ phases. ${ }^{40,41}$ These observations confirm that the Ag NPs still exist after deposition of $\mathrm{TiO}_{2}$ and no other crystal phase or $\mathrm{Ag}$ doped $\mathrm{TiO}_{2}$ phase are found. Fig. 3, 4 and S6† can provide the information that the deposition of the $\mathrm{TiO}_{2}$ layer can stabilize the Ag NPs at their location and no defect phases were generated during the deposition.

Top view SEM images of the samples with the structure perovskite layer $/ \mathrm{TiO}_{2} /$ (with and without) different sizes of $\mathrm{Ag}$ NPs/FTO/glass were recorded and presented in Fig. S7† to investigate the influence of Ag NPs on the morphology of perovskite layers. It is observed that the grain sizes of all the perovskite layers are roughly the same. For larger Ag NPs however an increasing density of tiny particles, lying on the perovskite surface, is observed. As shown later, the appearing particles have no influence on the transport length of minority charge carriers.

\section{Influence of Ag nanoparticles on ultra-thin perovskite solar cell}

From the results shown so far, incorporation of Ag NPs generates enhancement of $J_{\mathrm{sc}}$ and PCE and in parallel decrease of $V_{\mathrm{oc}}$. XPS measurements show that Ag NPs could act as recombination centers in the UTPSCs which might explain the decrease of $V_{\text {oc }}$, but the mechanism is still unclear. In this case, more measurements were employed to understand how the Ag NPs influences the performance of UTPSC. To understand the effect of $\mathrm{Ag}$ NPs on the charge transfer at the $\mathrm{CH}_{3} \mathrm{NH}_{3} \mathrm{PbI}_{3} / \mathrm{TiO}_{2}$ interface, SPV measurements were carried out. Fig. 5a shows the schematic structure of the samples used for SPV measurements. Fig. $5 \mathrm{~b}$ presents spectra of the in-phase and phase-shifted by $90^{\circ}$ SPV signals of the control sample and the $11 \mathrm{~nm}, 16 \mathrm{~nm}$ and $36 \mathrm{~nm} \mathrm{Ag}$ NP samples. The in-phase signals are positive for all the four samples which means that photo generated electrons were separated preferentially towards the $\mathrm{CH}_{3} \mathrm{NH}_{3} \mathrm{PbI}_{3} / \mathrm{TiO}_{2}$ interface. ${ }^{35}$ The in-phase signals and phase-shifted by $90^{\circ}$ signals having opposite sign shows that charge separation was caused by only one mechanism and the relaxation of the SPV signals is due to recombination. In this case, the decrease of both in-phase and phase-shifted by $90^{\circ}$ signals with implementation of Ag NPs can be attributed to the increase of recombination. The appearing surface particles (see, Fig. S7 $\dagger$ ) may also contribute to the recombination process. Phaseshifted by $90^{\circ}$ signals reducing stronger than in-phase signals indicates the enhancement of de-trapping probability of electrons. This can be due to the increase of contact between Ag NPs and $\mathrm{TiO}_{2}$ layer. Moreover, Ag NPs were not fully covered by the $\mathrm{TiO}_{2}$ layer, which lead to the direct contact between Ag NPs and perovskite layer. Hence, Ag NPs can support the channel for recombination between the de-trapped electrons from $\mathrm{TiO}_{2}$ layer and holes from the perovskite layer. This could be another reason in addition to the recombination centres for the decrease of $V_{\mathrm{oc}}$ in solar cells.

Fig. 5c shows the transport lengths of minority charge carriers in the control sample, $11 \mathrm{~nm}, 16 \mathrm{~nm}$ and $36 \mathrm{~nm} \mathrm{Ag} \mathrm{NP}$
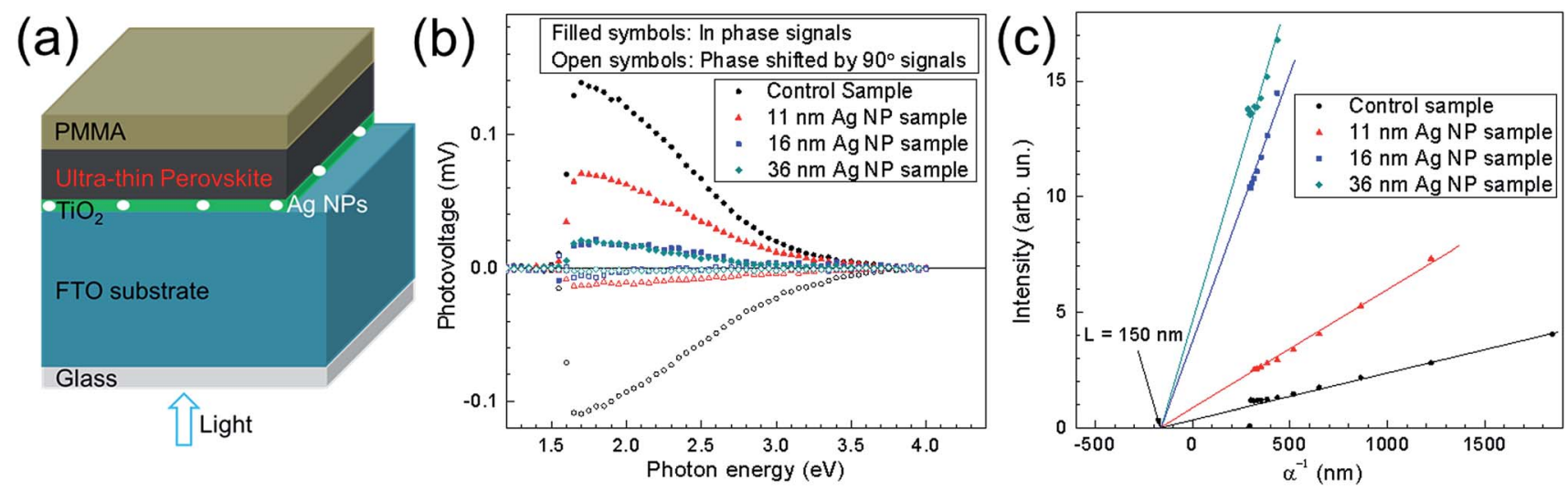

Fig. 5 (a) Schematic sample structure of PMMA/ultra-thin perovskite layer/ $/ \mathrm{TiO}_{2} / \mathrm{Ag} \mathrm{NPs} / \mathrm{FTO} /$ glass. (b) SPV spectra of the in-phase (filled symbols) and phase shifted by $90^{\circ}$ (open symbols) SPV signals of ultra-thin perovskite layers deposited on $\mathrm{TiO}_{2} /($ with and without) Ag NPs/FTO/ glass and coated with PMMA. (c) Goodman plots measured for constant SPV signals of ultra-thin perovskite layers deposited on $\mathrm{TiO}_{2} /($ with and without) Ag NPs/FTO/glass and coated with PMMA. 
samples derived from SPV. ${ }^{37}$ For all four samples, the transport lengths are around $150 \mathrm{~nm}$. This means: (1) the appearing surface particles do not influence the transport length of minority charge carriers and (2) the implementation of Ag NPs will not cause reduction of $J_{\text {sc }}$ originating from reduced diffusion lengths of charge carriers.

To further study the effect of $\mathrm{Ag}$ NPs on photocurrent enhancement, steady-state PL was measured for the control sample and the $11 \mathrm{~nm}, 16 \mathrm{~nm}$ and $36 \mathrm{~nm} \mathrm{Ag} \mathrm{NP}$ samples. There were no spiro-OMeTAD layer and Au back contact layer for the samples used in PL measurement. The schematic structure of the samples used for PL measurements is shown in Fig. 6a. Lasers with wavelengths of $362 \mathrm{~nm}$ and $504 \mathrm{~nm}$ were chosen to incident from the glass side for the measurement at $\mathrm{CH}_{3}$ $\mathrm{NH}_{3} \mathrm{PbI}_{3} / \mathrm{TiO}_{2}$ interface and at a deeper position within the $\mathrm{CH}_{3} \mathrm{NH}_{3} \mathrm{PbI}_{3}$ layer, respectively. The results are shown in Fig. $6 \mathrm{~b}$ and c. It is observed from Fig. $6 \mathrm{~b}$ that there is clear quenching of steady-state PL caused by Ag NPs, indicating improved charge separation at the $\mathrm{CH}_{3} \mathrm{NH}_{3} \mathrm{PbI}_{3} / \mathrm{TiO}_{2}$ interface and more electrons being trapped into the $\mathrm{TiO}_{2}$ layer. Correlating this to the above discussion, this can be partly due to the localized surface plasmon resonance (LSPR) of the Ag NPs. The quenching effect becomes stronger with increase of Ag NPs' sizes from $11 \mathrm{~nm}$ to $36 \mathrm{~nm}$. Using a laser with a wavelength of $504 \mathrm{~nm}$ corresponds to a deeper probing position within the perovskite layer. The effect of PL quenching is significant for the $36 \mathrm{~nm} \mathrm{Ag}$ NP sample as presented in Fig. 6c, but very slightly for the $11 \mathrm{~nm}$ and $16 \mathrm{~nm} \mathrm{Ag} \mathrm{NP} \mathrm{samples,} \mathrm{respectively.}$ The differences between these three samples are caused by the variation in the particle sizes. The $36 \mathrm{~nm} \mathrm{Ag} \mathrm{NPs} \mathrm{are} \mathrm{big}$ enough to have an influence on the deeper probing position of the PL, but the $11 \mathrm{~nm}$ and $16 \mathrm{~nm} \mathrm{Ag}$ NPs are too small to have such a clear impact. From the two PL measurements, the consistency on $36 \mathrm{~nm} \mathrm{Ag} \mathrm{NP} \mathrm{sample} \mathrm{and} \mathrm{difference} \mathrm{on} \mathrm{the}$ $11 \mathrm{~nm}$ and $16 \mathrm{~nm} \mathrm{Ag} \mathrm{NP}$ samples confirm that the effect of $\mathrm{Ag}$ NPs takes place only very near the Ag NPs. This finding agrees with localization of field enhancement due to the LSP effect. Hence, photocurrent enhancement could be attributed to localized surface plasmon resonances of Ag NPs and the enhanced extraction of electrons into the $\mathrm{TiO}_{2}$ layer. ${ }^{21}$

Fig. 7b shows the EQE for typical devices. Architecture of the devices is presented in Fig. 7a. The EQE spectrum from the $11 \mathrm{~nm}$ Ag NP sample and $16 \mathrm{~nm}$ Ag NP sample increased in the wavelength range from $350 \mathrm{~nm}$ to $700 \mathrm{~nm}$ compared to the control sample. The differences on EQE for the three samples indicate the broadband current enhancement by implementation of $11 \mathrm{~nm} \mathrm{Ag}$ NPs and $16 \mathrm{~nm} \mathrm{Ag}$ NPs. It has to be mentioned that the photocurrent enhancement shown in EQE spectra is not as significant as $22.2 \%$ for the enhancement of the average short-circuit current densities in $J-V$ characteristics (shown in Fig. 2c). The mismatch could be explained by (1) enhancement of photocurrent for the specified samples can be less than the average one and (2) the discrepancy between $J_{\text {sc }}$ measured by EQE and $J-V$ characteristics. Absorption spectra of the control sample and the $11 \mathrm{~nm} \mathrm{Ag} \mathrm{NP}$ and $16 \mathrm{~nm} \mathrm{Ag} \mathrm{NP} \mathrm{solar} \mathrm{cells} \mathrm{are}$ shown in Fig. 7c. It is observed that at wavelengths between $300 \mathrm{~nm}$ and $580 \mathrm{~nm}$ there is almost no difference for the three devices. At the wavelengths between $580 \mathrm{~nm}$ and $700 \mathrm{~nm}, \mathrm{Ag}$ NPs cause a slight absorption enhancement (in Fig. 7c) which contributes to the EQE improvement. From Fig. 3f, the resonance peak of Ag NPs would be expected at wavelengths around $580 \mathrm{~nm}$. Due to the change of medium surrounding the Ag NPs from air to $\mathrm{TiO}_{2}$, the resonance peak will however redshift which can explain the enhancement between 580 and $700 \mathrm{~nm}$ (see, Fig. S5 $\dagger$ ). Therefore, the resonant behavior of the Ag NPs contributes to the absorption and EQE enhancement of UTPSC in the longer wavelength range. But for shorter wavelength, other effects of the Ag NPs need to cause the enhancement of EQE. Compared to the absorption spectra, there is loss of EQE between $300 \mathrm{~nm}$ and $350 \mathrm{~nm}$ for all the solar cells. This is because the light is mainly absorbed by FTO substrate and $\mathrm{TiO}_{2}$ layer. It will be very promising if this part of light can also contribute to the performance of UTPSCs.

The results shown above give clear evidences for the encouraging finding that incorporation of Ag NPs into UTPSCs leads to enhancement of both charge separation and diffusion
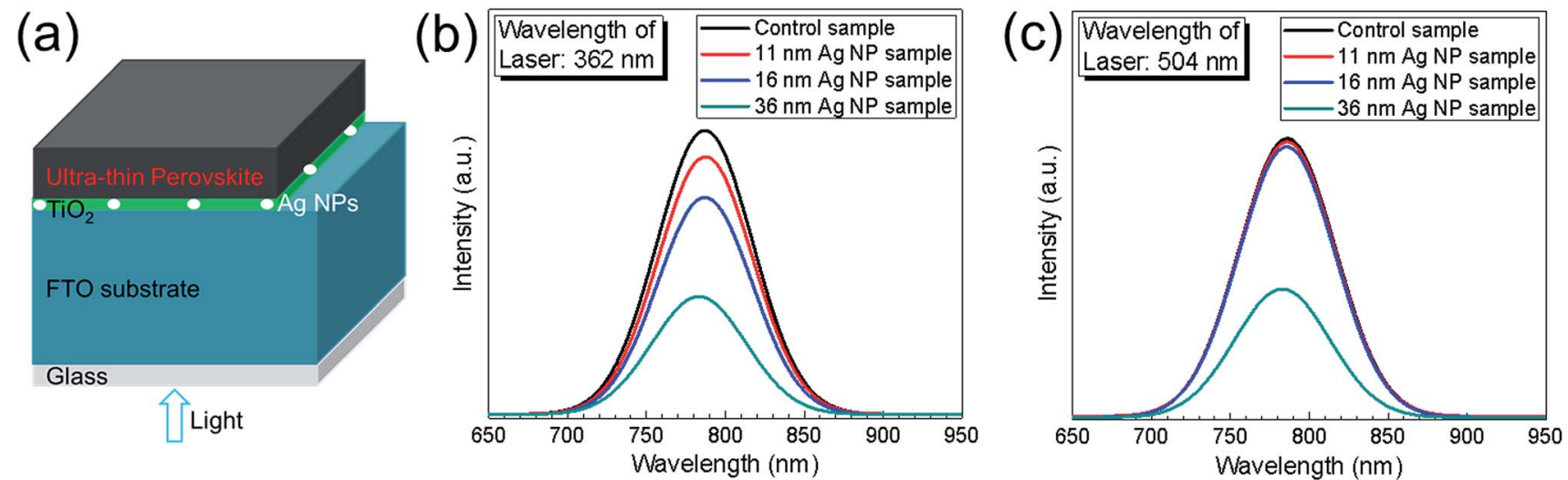

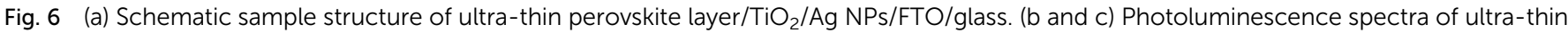
perovskite layers coated on $\mathrm{TiO}_{2} / \mathrm{FTO} /$ glass (control sample) and on $\mathrm{TiO}_{2} / \mathrm{Ag} \mathrm{NPs} / \mathrm{FTO} /$ glass (with different size Ag NPs, i.e., $11 \mathrm{~nm}, 16 \mathrm{~nm}$ and 36 $\mathrm{nm}$ ) samples. PL spectra at the perovskite/ $\mathrm{TiO}_{2}$ interface (b) and at deeper position from interface (c) were measured by laser with wavelengths of $362 \mathrm{~nm}$ and $504 \mathrm{~nm}$, respectively. 

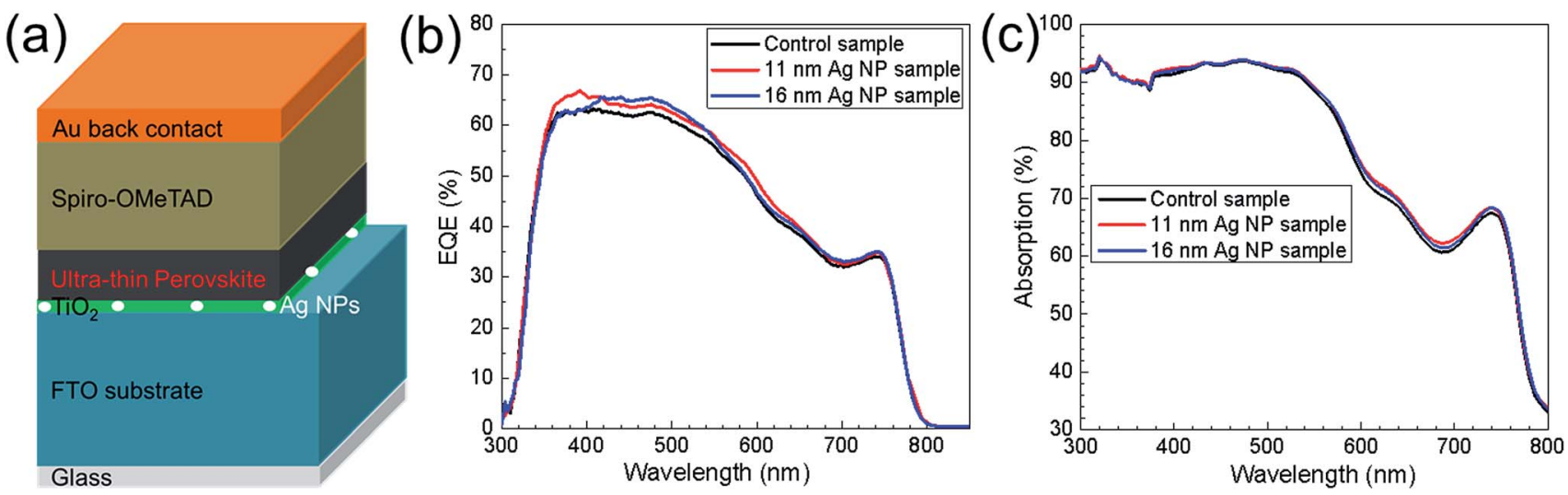

Fig. 7 (a) Schematic device structure of ultra-thin perovskite solar cell with incorporation of Ag nanoparticles at the $\mathrm{TiO}_{2} / \mathrm{FTO}$ interface. (b) EQE of the ultra-thin perovskite solar cells without (control sample), with $11 \mathrm{~nm}$ (11 nm Ag NP sample) and with $16 \mathrm{~nm}$ (16 nm Ag NP sample) Ag NPs. (c) UV-Vis spectra of the ultra-thin perovskite solar cells without (control sample), with $11 \mathrm{~nm}$ (11 nm Ag NP sample) and with $16 \mathrm{~nm}$ (16 nm Ag NP sample) Ag NPs.

of electrons into $\mathrm{TiO}_{2}$ layer surrounding the $\mathrm{Ag}$ NPs which will improve $J_{\text {sc }}$ of UTPSCs. This is very helpful for explaining how Ag NPs improve the performance of UTPSCs and very important for further improving the performance of UTPSCS. As not fully covered Ag NPs can act as recombination centers, electrons which were first trapped in $\mathrm{TiO}_{2}$ de-trap into Ag NPs and hence recombine with holes from the perovskite layer, leading to a decrease of $V_{\mathrm{oc}}$ and relatively also $J_{\mathrm{sc}}$. To overcome this drawback of Ag NPs, increasing the thickness of the $\mathrm{TiO}_{2}$ layer to fully cover the Ag NPs could be one possible way.

\section{Conclusions}

In this work, size and density controlled silver nanoparticles were implemented into ultra-thin perovskite solar cells (thickness of perovskite layer is only $\sim 140 \mathrm{~nm}$ ) by a low temperature spray chemical vapor deposition method (spray-CVD). This method is easy for large amount production of Ag NPs as well as compatible with the materials which are not able to bear high temperatures. A $J_{\mathrm{sc}}$ enhancement of around $22.2 \%$ was observed, as the average $J_{\mathrm{sc}}$ increased from $10.79 \mathrm{~mA} \mathrm{~cm}^{-2}$ for the control samples to $13.19 \mathrm{~mA} \mathrm{~cm}{ }^{-2}$ for the samples with $11 \mathrm{~nm} \mathrm{Ag}$ NPs. This leads to an increase of average PCE from $5.78 \%$ to $7.08 \%$, i.e., $22.5 \%$ relative. Quenching of steady-state $\mathrm{PL}$ indicates that charge separation and trapping of electrons into the $\mathrm{TiO}_{2}$ layer were enhanced at the $\mathrm{CH}_{3} \mathrm{NH}_{3} \mathrm{PbI}_{3} / \mathrm{TiO}_{2}$ interface, which contributed to the enhancement of $J_{\mathrm{sc}}$. Studies of XPS and SPV show that not fully covered Ag NPs can also work as recombination centers which lead to the decrease of $V_{\mathrm{oc}}$ and $J_{\mathrm{sc}}$. If this problem can be resolved, higher enhancements of $J_{\mathrm{sc}}$ and PCE of UTPSC can be expected. It's also expected that plasmonic Ag NPs can be applied for further improvement of UTPSCs.

\section{Acknowledgements}

Y. Liu is grateful to the China Scholarship Council for financial support.

\section{Notes and references}

1 H. S. Jung and N.-G. Park, Small, 2015, 11, 10-25.

2 W.-J. Yin, J.-H. Yang, J. Kang, Y. Yan and S.-H. Wei, J. Mater. Chem. A, 2015, 3, 8926-8942.

3 A. Kojima, K. Teshima, Y. Shirai and T. Miyasaka, J. Am. Chem. Soc., 2009, 131, 6050-6051.

4 NREL efficiency chart, http://www.nrel.gov/pv/assets/images/ efficiency_chart.jpg, accessed 7th November 2016.

5 J.-H. Im, C.-R. Lee, J.-W. Lee, S.-W. Park and N.-G. Park, Nanoscale, 2011, 3, 4088-4093.

6 H.-S. Kim, C.-R. Lee, J.-H. Im, K.-B. Lee, T. Moehl, A. Marchioro, S.-J. Moon, R. Humphry-Baker, J.-H. Yum, J. E. Moser, M. Grätzel and N.-G. Park, Sci. Rep., 2012, 2, 591.

7 M. M. Lee, J. Teuscher, T. Miyasaka, T. N. Murakami and H. J. Snaith, Science, 2012, 338, 643-647.

8 M. Liu, M. B. Johnston and H. J. Snaith, Nature, 2013, 501, 395-398.

9 H. Zhou, Q. Chen, G. Li, S. Luo, T.-b. Song, H.-S. Duan, Z. Hong, J. You, Y. Liu and Y. Yang, Science, 2014, 345, 542-546.

10 Z. Xiao, C. Bi, Y. Shao, Q. Dong, Q. Wang, Y. Yuan, C. Wang, Y. Gao and J. Huang, Energy Environ. Sci., 2014, 7, 2619-2623.

11 E. Della Gaspera, Y. Peng, Q. Hou, L. Spiccia, U. Bach, J. J. Jasieniak and Y.-B. Cheng, Nano Energy, 2015, 13, 249-257. 12 L. K. Ono, S. Wang, Y. Kato, S. R. Raga and Y. Qi, Energy Environ. Sci., 2014, 7, 3989-3993.

13 G. E. Eperon, V. M. Burlakov, A. Goriely and H. J. Snaith, ACS Nano, 2014, 8, 591-598.

14 F. Lang, M. A. Gluba, S. Albrecht, J. Rappich, L. Korte, B. Rech and N. H. Nickel, J. Phys. Chem. Lett., 2015, 6, 2745-2750.

15 H. A. Atwater and A. Polman, Nat. Mater., 2010, 9, 205-213. 16 J. A. Schuller, E. S. Barnard, W. Cai, Y. C. Jun, J. S. White and M. L. Brongersma, Nat. Mater., 2010, 9, 193-204.

17 V. E. Ferry, M. A. Verschuuren, H. B. Li, E. Verhagen, R. J. Walters, R. E. Schropp, H. A. Atwater and A. Polman, Opt. Express, 2010, 18, A237-A245. 
18 X. Chen, B. Jia, J. K. Saha, B. Cai, N. Stokes, Q. Qiao, Y. Wang, Z. Shi and M. Gu, Nano Lett., 2012, 12, 2187-2192.

19 X. Li, W. C. H. Choy, L. Huo, F. Xie, W. E. I. Sha, B. Ding, X. Guo, Y. Li, J. Hou, J. You and Y. Yang, Adv. Mater., 2012, 24, 3046-3052.

20 G. Yin, A. Steigert, P. Andrae, M. Goebelt, M. Latzel, P. Manley, I. Lauermann, S. Christiansen and M. Schmid, Appl. Surf. Sci., 2015, 355, 800-804.

21 Z. Lu, X. Pan, Y. Ma, Y. Li, L. Zheng, D. Zhang, Q. Xu, Z. Chen, S. Wang, B. Qu, F. Liu, Y. Huang, L. Xiao and Q. Gong, RSC Adv., 2015, 5, 11175-11179.

22 M. Qian, M. Li, X.-B. Shi, H. Ma, Z.-K. Wang and L.-S. Liao, J. Mater. Chem. A, 2015, 3, 13533-13539.

23 M. Saliba, W. Zhang, V. M. Burlakov, S. D. Stranks, Y. Sun, J. M. Ball, M. B. Johnston, A. Goriely, U. Wiesner and H. J. Snaith, Adv. Funct. Mater., 2015, 25, 5038-5046.

24 Z. Yuan, Z. Wu, S. Bai, Z. Xia, W. Xu, T. Song, H. Wu, L. Xu, J. Si, Y. Jin and B. Sun, Adv. Energy Mater., 2015, 1500038, DOI: 10.1002/aenm.201500038.

25 H.-L. Hsu, T.-Y. Juang, C.-P. Chen, C.-M. Hsieh, C.-C. Yang, C.-L. Huang and R.-J. Jeng, Sol. Energy Mater. Sol. Cells, 2015, 140, 224-231.

26 W. Zhang, M. Saliba, S. D. Stranks, Y. Sun, X. Shi, U. Wiesner and H. J. Snaith, Nano Lett., 2013, 13, 4505-4510.

27 Y. Liu, Y. Fu, T. Dittrich, R. Sáez-Araoz, M. Schmid, V. Hinrichs, M. C. Lux-Steiner and C.-H. Fischer, Thin Solid Films, 2015, 590, 54-59.

28 Y. Liu, P. Plate, V. Hinrichs, T. Köhler, M. Song, P. Manley, M. Schmid, P. Bartsch, S. Fiechter, M. C. Lux-Steiner and C.-H. Fischer, J. Nanopart. Res., submitted.
29 K. C. Pingali, D. A. Rockstraw and S. Deng, Aerosol Sci. Technol., 2005, 39, 1010-1014.

30 T. C. Pluym, Q. H. Powell, A. S. Gurav, T. L. Ward, T. T. Kodas, L. M. Wang and H. D. Glicksman, J. Aerosol Sci., 1993, 24, 383-392.

31 S.-J. Shih and I. C. Chien, Powder Technol., 2013, 237, 436441.

32 N. Kumar, F. Alam and V. Dutta, J. Alloys Compd., 2014, 585, 312-317.

33 N. J. Jeon, J. H. Noh, Y. C. Kim, W. S. Yang, S. Ryu and S. I. Seok, Nat. Mater., 2014, 13, 897-903.

34 T. Dittrich, C. Awino, P. Prajongtat, B. Rech and M. C. LuxSteiner, J. Phys. Chem. C, 2015, 119, 23968-23972.

35 A. Naikaew, P. Prajongtat, M. C. Lux-Steiner, M. Arunchaiya and T. Dittrich, Appl. Phys. Lett., 2015, 106, 232104.

36 A. M. Goodman, J. Appl. Phys., 1961, 32, 2550-2552.

37 T. Dittrich, F. Lang, O. Shargaieva, J. Rappich, N. H. Nickel, E. Unger and B. Rech, Appl. Phys. Lett., 2016, 109, 073901.

38 W. E. I. Sha, X. Ren, L. Chen and W. C. H. Choy, Appl. Phys. Lett., 2015, 106, 221104.

39 M. Long, Z. Chen, T. Zhang, Y. Xiao, X. Zeng, J. Chen, K. Yan and J. Xu, Nanoscale, 2016, 8, 6290-6299.

40 M. B. Suwarnkar, R. S. Dhabbe, A. N. Kadam and K. M. Garadkar, Ceram. Int., 2014, 40, 5489-5496.

41 M. Harikishore, M. Sandhyarani, K. Venkateswarlu, T. A. Nellaippan and N. Rameshbabu, Procedia Mater. Sci., 2014, 6, 557-566. 